\title{
Increasing dependency of older people in nursing homes is associated with need for dental treatments
}

This article was published in the following Dove Press journal:

Neuropsychiatric Disease and Treatment

2 December 2014

Number of times this article has been viewed

\author{
Andreas Zenthöfer \\ Peter Rammelsberg \\ Tomas Cabrera \\ Alexander Jochen Hassel \\ Department of Prosthodontics, \\ Dental School, University \\ of Heidelberg, Heidelberg, Germany
}

\begin{abstract}
To determine relationships between the need for dental treatments of institutionalized elderly people and cognitive impairment and the general level of care needed. Two hundred and sixty-eight residents of long-term care facilities in Germany were included in this study. Age, sex, diseases, number of frequently taken drugs, and location of the long-term care facility of the participants were recorded. For each participant, the need for care was assessed by use of the Barthel index (BI). Cognitive impairment was evaluated by use of the mini-mental state examination (MMSE). To assess dental treatment needs, the revised oral assessment guide (ROAG) was applied for different oral health conditions, which were rated "healthy" or "treatment needed". Spearman correlations were performed to evaluate associations between BI and MMSE and dental treatment needs. Statistical analysis revealed significant associations of BI $(P<0.001)$ and MMSE $(P=0.015)$ with the ROAG score. Increasing dependency and decreasing cognitive ability worsen oral health and increase the need for dental treatment.
\end{abstract}

Keywords: elderly, dependency, Barthel index, treatment needs, oral health

\section{Introduction}

The proportion of people 65 years and older among the German population has increased from $14.9 \%$ in 1990 to $21 \%$ in recent years, and aging of the population is a long-term trend. ${ }^{1}$ Consequently, these demographic changes have led to a larger number of elderly people in need of care. Today, of the 2.5 million Germans needing care, 743,000 are living in long-term care facilities. ${ }^{2}$ Research has often revealed poor oral hygiene and oral health among elderly people in long-term care. In particular, high prevalence of periodontal diseases, ill-fitting dentures, and root caries have been reported by several authors. ${ }^{3-6}$ The evidence suggests not only that oral health has a substantial effect on chewing function and therefore, nutrition, ${ }^{7,8}$ but also that it can affect general health. Multiple associations have been found between poor oral health and systemic diseases. ${ }^{9-11}$ It has been reported that periodontal diseases are associated with a greater risk of cardiac infarction and stroke ${ }^{9-11}$ and diminished oral hygiene is linked to pneumonia. ${ }^{12}$ Little has been reported in the literature about the circumstances leading to worsening of the oral health of elderly people, however. In general, elderly people are a very heterogeneous group with a variety of cognitive and functional impairments..$^{8,13-15}$ It has been pointed out that the decline in oral health is associated with increasing cognitive impairment caused by the onset of dementia. ${ }^{8,13-15}$ It has been stated that the likelihood of deterioration of oral health is also linked to caregivers' lack of knowledge of very complex dental treatment (eg, implant-supported dentures). ${ }^{16,17}$ Moreover, estimation of the specific and changing needs of elderly people challenges caregivers who have to deal with many 
different tasks, for example washing, dressing, toileting, feeding, documenting care, and coordinating physicians' visits. ${ }^{17}$ Another reason for the many oral problems of aged people is the limited use of dental care services by residents of long-term care facilities, ${ }^{18-20}$ which is associated with such general barriers as cost, education, family members' lack of awareness of the need for dental services, transportation difficulties, and self-perceived need for oral care. ${ }^{18-20}$ Apart from these considerations, however, few investigations of community-dwelling elderly people found associations between dependency and oral health and/or dental treatment needs. ${ }^{8,15}$ It has been shown that senior citizens who require a high level of care and who cannot function completely independently have fewer of their own teeth, no dentures, and suffer more frequently from dysphagia. ${ }^{8}$ One study of an institutionalized elderly community affirmed this relationship. Worse oral hygiene and more caries have been reported among those in need of care. ${ }^{21}$ Nevertheless, as far as the authors are aware, there has been no systematic investigation of associations between the level of care needed and/or cognitive ability and the overall dental treatment needs of elderly people in long-term care facilities. The purpose of this study was, therefore, to evaluate relationships between demographic variables, cognitive ability, and the general level of care needed, as measured by use of the Barthel index (BI), with the dental treatment needs and/or oral health of institutionalized elderly people.

\section{Materials and methods Study population}

This study was approved by the local review board of the University of Heidelberg (approval number S-002/2012). It was performed in 13 long-term care facilities in southwestern Germany, in seven urban and six rural locations selected as representative of the state of Baden-Württemberg by the Ministry of Social Affairs (see Acknowledgments). All residents received written study information by mail. An event was also held to inform all residents and their caregivers about the study. No specific exclusion criteria were formulated, it was only required that participants signed a consent form. If the residents did not have the capacity to give consent, their legal guardians decided on their behalf. Two hundred and sixty-eight individuals agreed to participate and were included in the study.

\section{Assessment tools}

Age, sex, number of diseases, and frequently used drugs were obtained from the medical records of each participant.

\section{Dental treatment needs}

All dental examinations were conducted by two dentists experienced in epidemiologic surveys. Dental treatment needs were assessed by use of the revised oral assessment guide (ROAG), ${ }^{22,23}$ a standardized tool for evaluation of oral health that includes assessment of voice, lips, mucous membranes, gums, cleanliness of teeth and/or dentures, saliva, swallowing, caries, and the fitting, retention, and condition of dentures (12 items). The ROAG is also validated for use by physicians and caregivers. ${ }^{22,23}$ Each aspect of the oral health conditions is rated as healthy, to be monitored, or needs treatment. In previous studies, this three-point scale was used to monitor oral health to enable timely detection and treatment of oral shortcomings as they arose. ${ }^{23-25}$ In this study, ROAG scores were divided into healthy and to be monitored ( 0 ) and dental treatment required (1). The total ROAG score could therefore range from 0 to 12 . Prior to the beginning of the study the two examiners (see above) were calibrated in the use of ROAG by applying it to elderly patients attending the Department of Prosthodontics. To determine reliability, inter-examiner agreement between the two examiners was evaluated. Thirty of the participants were randomly selected and independently examined by use of the ROAG. Cronbach's alpha was calculated for the raters and found to be 0.945 .

\section{Level of care needed}

To assess the level of care needed, the BI was used. ${ }^{26}$ This instrument, which was created for evaluation of the functional capacity of elderly communities, ${ }^{27}$ is widely used in studies of epidemiology. ${ }^{8,15}$ The BI rates dependence in the activities of daily life from 0 to 100 , where 0 is indicative of total dependence and 100 of total independence. In this study, the BI was determined on the basis of the usual categorization in accordance with cut-offs described in a previous study. ${ }^{28}$ The BI was determined by the participants' caregivers, as suggested in a previous study. ${ }^{29}$

\section{Cognitive impairment}

For evaluation of participants' cognitive impairment, the mini-mental state examination (MMSE) was conducted by four psychologists (see Acknowledgments). Before and during the study, the psychologists were trained by investigating psychiatric patients attending the memory clinic of the University of Heidelberg. Further assessment of reliability was not performed. The MMSE has, however, proved valid for the detection of cognitive impairment and is also widely used clinically as part of routine dementia screening. ${ }^{30}$ In previous 
studies investigating correlations with oral health, ${ }^{14,15}$ the continuous or categorized MMSE was primarily used, even though other methods are available for screening of cognitive state, eg, the Global Deterioration Scale. ${ }^{31}$ We also, therefore, decided to use the MMSE to enable comparison of data. The MMSE is conducted by asking participants to solve 30 tasks within the categories: orientation, registration, attention, calculation, recall, and language. Correctly performed exercises are rated with 1 point, whereas the score for failure is 0 . Participants can therefore obtain scores ranging from 0 to 30 , with high scores being indicative of healthy subjects. ${ }^{30}$

\section{Statistical evaluation}

Data from case record forms were entered in two databases by two operators and checked for agreement. For descriptive purposes, frequencies, means (standard deviation [SD]), or medians ( $25 \% / 75 \%$ quartiles) were plotted for age, sex, diseases, number of frequently taken drugs, location of the long-term care facility, and ROAG, MMSE, and BI scores, where appropriate. Because the ROAG score was found to violate the assumption of normal distribution (KolmogorovSmirnov test; $P=0.001$ ), nonparametric statistics were used (Spearman correlation, $U$-test, and Kruskal-Wallis test). The number of dental treatments required for different cutoff values was also studied: BI: 0-50 (severe dependency), 51-75 (moderate dependency), and 76-100 (mild or no impairment). ${ }^{28}$ The level for local statistical significance was set at $P<0.05$. Because of the explorative nature of the study, no correction of alpha was performed. All statistical analysis was performed by use of SPSS (v19.0; IBM Corporation, Armonk, NY, USA).

\section{Results}

None of the included participants missed the investigations and was lost to statistical analysis. Thus, complete data for 268 participants ( $70.5 \%$ female) were available for statistical analysis. The mean age of the participants was 83.1 years (SD 9.1; range 51-102). The mean number of own teeth was 6.8 (SD 8.3) and $60.1 \%$ of the participants had their own teeth. Members of the study population had a mean of 3.4 diseases (SD 2.3) and were taking a mean of 6.6 (SD 3.5) permanent medications. Of the participants, $60.8 \%$ lived in urban long-term care facilities and $92.9 \%$ had at least one oral health condition in need of treatment. The median number of dental conditions requiring treatment, as measured by use of the ROAG, was $2.0(25 \% / 75 \%$ quartile $2.0 / 3.0)$. The median ROAG score for female participants was $2.0(25 \% / 75 \%$ quartile 2.0/3.0); for males it was 2.0 (2.0/4.0). For participants living in urban long-term care homes, the median ROAG was $2.0(25 \% / 75 \%$ quartile $2.0 / 3.0)$; for those living in rural long-term care homes, it was 3.0 (2.0/4.0). The mean MMSE (SD) among the participants was 17.3 (8.1); the mean BI (SD) was 46.9 (30.3). More details are given in Table 1.

Age $(P=0.673)$, sex $(P=0.617)$, diseases $(P=0.650)$, medications $(P=0.944)$, and location of the long-term care facility $(P=0.421)$ had no significant effect on ROAG score. Statistical analysis revealed significant associations of BI (Spearman correlation $-0.241 ; P<0.001$ ) and MMSE (Spearman correlation $-0.178 ; P=0.015$ ) with ROAG score (Table 1).

In the different BI categories, median ( $25 \% / 75 \%$ quartile) ROAG scores were 3.0 (2.0/4.0) for participants with severe

Table I Characteristics of the sample and statistical correlation with ROAG score $(n=268)$

\begin{tabular}{|c|c|c|c|c|}
\hline & $\begin{array}{l}\text { Frequency } \\
\text { (\%) }\end{array}$ & $\begin{array}{l}\text { Mean } \\
\text { (SD) }\end{array}$ & $\begin{array}{l}\text { ROAG score (median } \\
\text { [25\%/75\% quartile]) }\end{array}$ & $\begin{array}{l}\text { Significance } \\
(P \text {-value })\end{array}$ \\
\hline Age & - & $83.1(9.1)$ & - & $0.673^{a}$ \\
\hline \multicolumn{5}{|l|}{ Sex } \\
\hline Female & $189(70.5 \%)$ & - & $2.0(2.0 / 3.0)$ & \\
\hline Male & 79 (29.5\%) & - & $2.0(2.0 / 4.0)$ & $0.617^{\mathrm{b}}$ \\
\hline Number of diseases & - & $3.4(2.3)$ & - & $0.650^{c}$ \\
\hline Number of drugs & - & $6.6(3.5)$ & - & $0.944^{d}$ \\
\hline \multicolumn{5}{|c|}{ Location of long-term care home } \\
\hline Urban & $163(60.8 \%)$ & - & $2.0(2.0 / 3.0)$ & \\
\hline Rural & 105 (39.2\%) & - & $3.0(2.0 / 4.0)$ & $0.42 \mathrm{I}^{\mathrm{b}}$ \\
\hline MMSE & - & $17.3(8.1)$ & - & $0.015^{e}$ \\
\hline $\mathrm{BI}$ & - & $46.9(30.3)$ & - & $<0.00 I^{f}$ \\
\hline
\end{tabular}

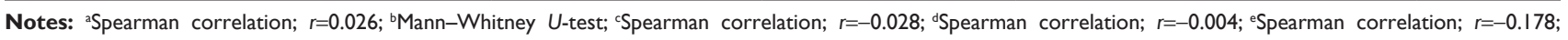
'Spearman correlation; $r=-0.24 \mathrm{I}$. Bold indicates statistically significant $P$-values.

Abbreviations: BI, Barthel index; MMSE, mini-mental state examination; ROAG, revised oral assessment guide; SD, standard deviation. 
Table 2 Median ROAG scores (25\%/75\% quartile) in the different Bl categories $(n=268)$

\begin{tabular}{lll}
\hline & $\begin{array}{l}\text { ROAG score (median } \\
[\mathbf{2 5} \% / \mathbf{7 5} \% \text { quartile }])\end{array}$ & $\begin{array}{l}\text { Significance } \\
(\mathbf{P} \text {-value })\end{array}$ \\
\hline $\begin{array}{l}\text { 0-50 } \\
\text { (severe dependency) }\end{array}$ & $3.0(2.0 / 4.0)$ & $\mathbf{P}=\mathbf{0 . 0 0} \mathrm{I}^{\mathrm{a}}$ \\
$5 \mathrm{I}-70$ & $2.0(2.0 / 3.0)$ & \\
(moderate dependency) & & \\
7I-100 & $2.0(\mathrm{I} .0 / 3.0)$ & \\
(mild to no dependency) & & \\
\hline
\end{tabular}

Notes: a Kruskal-Wallis test. Bold indicates a statistically significant $P$-value. Abbreviations: $\mathrm{Bl}$, Barthel index; ROAG, revised oral assessment guide.

dependency (BI <50), $2.0(2.0 / 3.0)$ for those with moderate dependency (BI 51-70), and 2.0 (1.0/3.0) for those with no to mild dependency $(\mathrm{BI}>70)$. ROAG scores were significantly different in the three categories $(P=0.001)$. Detailed results are presented in Table 2.

Comparison of the BI scores for single items of the ROAG for participants who required dental treatment showed that median BI was significantly lower for participants in need of treatment for the voice, lips, tongue, gums, saliva, and caries $(P<0.05$; Table 3$)$.

\section{Discussion}

The results of this study suggest that participants' greater need of care and decreasing cognitive ability are significantly associated with increased dental treatment needs. This is in accordance with previous findings among noninstitutionalized elderly people. ${ }^{8,13-15}$ Intercorrelation of care dependency and cognitive state were also revealed by a study of institutionalized elderly people. ${ }^{21}$ However, to the knowledge of the authors, this is the first study that systematically evaluated a wide spectrum of oral issues by use of a screening instrument also applicable for nondental professionals. The study found worse oral hygiene and more caries among participants with diminished functional and cognitive capacity than among healthy subjects. Nevertheless, in this recent study, specific oral problems associated with mucous membranes, fitting, retention, and condition of dentures, and oral and/or denture hygiene occurred irrespective of the level of dependency. This might be because of general barriers to oral health provision among institutionalized elderly people, for example cost, education, lack of awareness of family members of the need to use dental services, and transport difficulties. ${ }^{18-20}$ Another reason could be reduced self-perceived need for oral care. ${ }^{18-20}$ Deterioration can, moreover, also occur as a result of caregivers' inadequate knowledge about specific dental needs. Oral problems might also deteriorate as a result of caregivers' lack of time, because they must deal with many other tasks, and oral conditions frequently have no priority. ${ }^{17}$ In this context, it should be pointed out that these participants had a median of two oral health conditions that required treatment, and perfect oral health was observed for $7.1 \%$ only. This is in agreement with results from other studies that reported a variety of oral shortcomings among institutionalized elderly people. ${ }^{3-6} \mathrm{Nev}-$ ertheless, this study identified functional capacity as a variable predicting additional oral problems, and therefore, treatment needs. Severe dependency $(\mathrm{BI}<50)$, especially, seemed to be linked to several oral problems. Old people

Table 3 Median (25\%/75\% quartile) BI for the single items of ROAG ( $n=268)$

\begin{tabular}{|c|c|c|c|c|c|}
\hline \multirow[t]{2}{*}{ ROAG item } & \multicolumn{2}{|c|}{ No treatment needed } & \multicolumn{2}{|c|}{ Treatment needed } & \multirow{2}{*}{$\begin{array}{l}\text { Significance } \\
(P \text {-value })^{\mathrm{a}}\end{array}$} \\
\hline & $\begin{array}{l}\text { Median } \\
(25 \% / 75 \%)\end{array}$ & $\begin{array}{l}\text { Frequency } \\
\text { (\%) }\end{array}$ & $\begin{array}{l}\text { Median } \\
(25 \% / 75 \%)\end{array}$ & $\begin{array}{l}\text { Frequency } \\
\text { (\%) }\end{array}$ & \\
\hline Voice & $50.0(25.0 / 80.0)$ & $225(84.0 \%)$ & $10.0(5.0 / 25.0)$ & $43(16.0 \%)$ & $P<0.00$ I \\
\hline Lips & $45.0(20.0 / 75.0)$ & $264(99.0 \%)$ & $10.0(6.3 / 32.5)$ & $4(1.0 \%)$ & $P=0.03 I$ \\
\hline Mucous membranes & $45.0(20.0 / 75.0)$ & $259(97.0 \%)$ & $15.0(10.0 / 65.0)$ & $9(3.0 \%)$ & $P=0.145$ \\
\hline Tongue & $45.0(20.0 / 75.0)$ & $261(97.4 \%)$ & $15.0(10.0 / 20.0)$ & $7(2.6 \%)$ & $P=0.008$ \\
\hline Gums (dentates only) $n=161$ & $65.0(35.0 / 80.0)$ & $83(51.6 \%)$ & $30.0(15.0 / 55.0)$ & $78(48.4 \%)$ & $\mathbf{P}<\mathbf{0 . 0 0 I}$ \\
\hline Cleanliness of teeth and/or dentures & $42.5(18.8 / 80.0)$ & $66(24.6 \%)$ & $42.5(20.0 / 75.00)$ & $202(75.4 \%)$ & $P=0.915$ \\
\hline Saliva & $45.0(20.0 / 75.0)$ & $261(97.4)$ & $10.0(5.0 / 50.0)$ & $7(2.6 \%)$ & $P=0.030$ \\
\hline Swallow & $45.0(20.0 / 75.0)$ & $264(99.0 \%)$ & $17.5(6.3 / 36.3)$ & $4(1.0 \%)$ & $P=0.067$ \\
\hline Caries (dentates only) $n=161$ & $60.0(25.0 / 80.0)$ & $75(46.6 \%)$ & $40.0(15.0 / 65.0)$ & $86(53.4 \%)$ & $P=0.012$ \\
\hline Fitting of dentures $n=195$ & $57.5(20.0 / 80.0)$ & $\mathrm{n}=68(34.9 \%)$ & $45.0(25.0 / 75.0)$ & 127 (65.1\%) & $P=0.87 I$ \\
\hline Retention of dentures $n=195$ & $50.0(21.3 / 80.0)$ & $\mathrm{n}=108(55.4 \%)$ & $40.0(25.0 / 75.0)$ & $87(44.6 \%)$ & $P=0.244$ \\
\hline $\begin{array}{l}\text { Condition of denture basis or retention } \\
\text { elements } n=195\end{array}$ & $45.0(20.0 / 80.0)$ & $n=|7|(87.7 \%)$ & $47.5(31.3 / 70.0)$ & $\mathrm{n}=24(12.3 \%)$ & $P=0.961$ \\
\hline
\end{tabular}

Notes: a Mann-Whitney $U$-test on $\mathrm{BI}$ differences. Bold indicates statistically significant $P$-values.

Abbreviations: $\mathrm{BI}$, Barthel index; ROAG, revised oral assessment guide. 
with their own teeth also suffer from higher prevalence of caries and such gum diseases as gingivitis and periodontitis. This is relevant because many aged people now have more of their own teeth remaining than in previous decades. ${ }^{32}$ One might also expect systemic diseases to have a substantial effect on dental treatment needs. It has been stressed that elderly people suffering from multiple comorbidities accept their declining oral health as a part of aging, and therefore, as an unrecoverable condition. ${ }^{18,33}$ Further, some more or less asymptomatic oral problems (ie, periodontitis) seem, subjectively, to be irrelevant, or elderly people cope with them, ${ }^{34,35}$ whereas others substantially affect quality of life. ${ }^{36}$ It should, however, be emphasised that $\sim 90 \%$ of the participants in this study had at least one disease. Nonetheless, the levels of care needed identified for the single dental treatment needs as measured by ROAG allow a prediction of seniors' dependency levels at which they are especially prone to specific oral diseases.

Furthermore, no difference was detected between participants' dental treatment needs in rural and urban long-term care homes. In one study that investigated the association of living in a rural or urban long-term care home with oral health, the authors showed that urban location of the longterm care home is a predictor of use of dentures by edentulous elderly people. ${ }^{20}$ This might be related to uneven distribution of dentists throughout urban and rural areas of Germany, although this was not confirmed by our study.

Another point worth discussing is use of the ROAG for oral examinations. The ROAG has three relevant advantages over other instruments. First, it covers a wide range of important aspects of oral health; second, it is validated for use by non-dentists, which gives physicians and caregivers - who often have more frequent contact with old people than dentists - the opportunity to estimate dental treatment needs; and, third, applying the ROAG is very quick ( $\sim 10$ minutes). ${ }^{22,23}$ Nevertheless, although the ROAG is an instrument recommended for screening oral conditions in elderly people, it has its limitations. The ROAG covers some shortcomings of oral health (ie, pathologies concerning lips, voice, saliva) that were fortunately not highly prevalent in this specific study community. Subsequently, these items show a rather unbalanced ratio of "treatment needed" and "no treatment needed" groups, which could have led to statistical bias. Nevertheless, participants with pathologic findings in these categories consistently showed high levels of care dependency. This is as expected, ${ }^{8}$ and underlines the accuracy of the instrument. Nonetheless, a more specific instrument may have resulted in a more specific outcome, but might have also yielded an underestimation of relevant but less frequent pathologies. To this end, to the knowledge of the authors, currently no other standardized assessment tool exists that would be more specific for the community evaluated in this study.

\section{Study limitations}

It should be borne in mind that participants were not preselected, and therefore, 16 participants were younger than 65 years and should, strictly speaking, not be classified as old persons. Because they lived in a long-term care home and needed care, it seemed valuable to include results for these participants in this paper, as also discussed by Dolan and Atchison. ${ }^{18}$

\section{Conclusion}

Within its limitations, this study found the need for oral treatment was very common among institutionalized old people. Increasing dependency and decreasing cognitive ability lead to diminished oral health and many dental treatment needs. Intensive monitoring of oral health among the most dependent elderly population is therefore recommended to enable recognition and treatment of oral problems at an early stage.

\section{Acknowledgments}

We would like to thank all the participants in this study for their patience. We are grateful to the participating nursing homes for their kind support, to the Ministry of Social Affairs of Baden-Württemberg (Sozialministerium BadenWürttemberg) for funding the study, and to Ian Davies, copy editor, for English language revision.

\section{Disclosure}

The authors report no conflicts of interest in this work.

\section{References}

1. Eurostat. Demography report 2010. Older, more numerous and diverse Europeans. Luxembourg: Publications Office of the European Union; 2011. Available from: http://epp.eurostat.ec.europa.eu/cache/ITY_OFFPUB/ KE-ET-10-001/EN/KE-ET-10-001-EN.PDF. Accessed September 24, 2014.

2. Statistisches Bundesamt. Pflegestatistik. Pflege im Rahmen der Pflegeversicherung: Deutschlandergebnisse. Wiesbaden: Statistisches Bundesamt; 2011. German.

3. McMillan AS, Wong MC, Lo EC, Allen PF. The impact of oral disease among the institutionalized and non-institutionalized elderly in Hong Kong. J Oral Rehabil. 2003;30(1):46-54.

4. Montal S, Tramini P, Triay JA, Valcarcel J. Oral hygiene and the need for treatment of the dependent institutionalized elderly. Gerodontology. 2006;23(2):67-72.

5. Chalmers JM, Carter KD, Spencer AJ. Caries incidence and increments in Adelaide nursing home residents. Spec Care Dentist. 2005;25(2): 96-105. 
6. Offenbacher S, Barros SP, Singer RE, Moss K, Williams RC, Beck JD. Periodontal disease at the biofilm-gingival interface. J Periodontol. 2007;78(10):1911-1925.

7. Bradbury J, Thomason JM, Jepson NJ, et al. Perceived chewing ability and intake of fruit and vegetables. J Dent Res. 2008;87(8): $720-725$.

8. Furuta M, Komiya-Nonaka M, Akifusa S, et al. Interrelationship of oral health status, swallowing function, nutritional status, and cognitive ability with activities of daily living in Japanese elderly people receiving home care services due to physical disabilities. Community Dent Oral Epidemiol. 2013;41(2):173-181.

9. Beck J, Garcia R, Heiss G, Vokonas PS, Offenbacher S. Periodontal disease and cardiovascular disease. J Periodontol. 1996;67(Suppl 10): $1123-1237$.

10. Pussinen PJ, Alfthan G, Rissanen H, Reunanen A, Asikainen S, Knekt P. Antibodies to periodontal pathogens and stroke risk. Stroke. 2004;35(9):2020-2023.

11. Dörfer CE, Becher H, Ziegler CM, et al. The association of gingivitis and periodontitis with ischemic stroke. J Clin Periodontol. 2004; 31(5):396-401.

12. Terpenning MS, Taylor GW, Lopatin DE, Kerr CK, Dominguez BL, Loesche WJ. Aspiration pneumonia: dental and oral risk factors in an older veteran population. $J$ Am Geriatr Soc. 2001;49(5): 557-563.

13. Ship JA, Puckett SA. Longitudinal study on oral health in subjects with Alzheimer's disease. J Am Geriatr Soc. 1994;42(1):57-63.

14. Chalmers JM, Carter KD, Spencer AJ. Caries incidence and increments in community-living older adults with and without dementia. Gerodontology. 2002;19(2):80-94.

15. Purandare N, Woods E, Butler S, et al. Dental health of communityliving older people attending secondary healthcare: a cross-sectional comparison between those with and without diagnosed mental illness. Int Psychogeriatr. 2010;22(3):417-425.

16. Saunders RH Jr. Implant or bridge for older adults: some additional thoughts. Spec Care Dentist. 2007;27(1):5.

17. Adams R. Qualified nurses lack adequate knowledge related to oral health, resulting in inadequate oral care of patients on medical wards. $J$ Adv Nurs. 1999;24(3):552-560.

18. Dolan TA, Atchison KA. Implications of access, utilization, and need for oral health care by the non-institutionalized and institutionalized elderly on the dental delivery system. J Dent Educ. 1993;57(12):876-887.

19. Dolan TA, Atchison K, Huynh TN. Access to dental care among older adults in the United States. J Dent Educ. 2005;69(9):961-974.

20. Matthews DC, Clovis JB, Brillant MG, et al. Oral health status of long-term care residents-a vulnerable population. J Can Dent Assoc. 2012;78:c3.

21. Zuluaga DJ, Ferreira J, Montoya JA, Willumsen T. Oral health in institutionalised elderly people in Oslo, Norway and its relationship with dependence and cognitive impairment. Gerodontology. 2012;29(2):e420-e426.
22. Andersson P, Hallberg IR, Renvert S. Inter-rater reliability of an oral assessment guide for elderly patients residing in a rehabilitation ward. Spec Care Dentist. 2002;22(5):181-186.

23. Hassel AJ, Leisen J, Rolko C, Rexroth W, Ohlmann B, Rammelsberg P. [Clinical assessment of oral health between physician and dentist - a pilot study on inter-examiner reliability]. Z Gerontol Geriatr. 2008;41(2): 132-138. German.

24. Hanne K, Ingelise T, Linda C, Ulrich PP. Oral status and the need for oral health care among patients hospitalised with acute medical conditions. J Clin Nurs. 2012;21(19-20):2851-2859.

25. Ribeiro MT, Ferreira RC, Vargas AM, e Ferreira EF. Validity and reproducibility of the revised oral assessment guide applied by community health workers. Gerodontology. 2014;31(2):101-110.

26. Mahoney FI, Barthel DW. Functional evaluation: the Barthel index. $M d$ State Med J. 1965;14(1):61-65.

27. Wade DT, Collin C. The Barthel ADL Index: a standard measure of physical disability? Int Disabil Stud. 1988;10(2):64-67.

28. Supervía A, Aranda D, Márquez MA, Aguirre A, Skaf E, Gutiérrez J. Predicting length of hospitalisation of elderly patients, using the Barthel Index. Age Ageing. 2008;37(3):339-342.

29. Collin C, Wade DT, Davies S, Horne V. The Barthel ADL Index: a reliability study. Int Disabil Stud. 1988;10(2):61-63.

30. Folstein MF, Folstein SE, McHugh PR. "Mini-mental state". A practical method for grading the cognitive state of patients for the clinician. J Psychiatr Res. 1975;12(3):189-198.

31. Reisberg B, Ferris SH, de Leon MJ, Crook T. The Global Deterioration Scale for assessment of primary degenerative dementia. Am J Psychiatry. 1982;139(9):1136-1139.

32. Michaelis W, Schiffner U. Vierte Deutsche Mundgesundheitsstudie IV, Institut der deutschen Zahnärzte. Cologne: Deutscher Ärzte-Verlag; 2006. German.

33. Castrejón-Pérez RC, Borges-Yáñez SA, Gutiérrez-Robledo LM, AvilaFunes JA. Oral health conditions and frailty in Mexican communitydwelling elderly: a cross sectional analysis. BMC Public Health. 2012;12:773.

34. Locker D, Gibson B. Discrepancies between self-ratings of and satisfaction with oral health in two older adult populations. Community Dent Oral Epidemiol. 2005;33(4):280-288.

35. Piuvezam G, de Lima KC. Self-perceived oral health status in institutionalized elderly in Brazil. Arch Gerontol Geriatr. 2012;55(1):5-11.

36. John MT, Koepsell TD, Hujoel P, Miglioretti DL, LeResche L, Micheelis W. Demographic factors, denture status and oral healthrelated quality of life. Community Dent Oral Epidemiol. 2004;32(2): $125-132$.
Neuropsychiatric Disease and Treatment

\section{Publish your work in this journal}

Neuropsychiatric Disease and Treatment is an international, peerreviewed journal of clinical therapeutics and pharmacology focusing on concise rapid reporting of clinical or pre-clinical studies on a range of neuropsychiatric and neurological disorders. This journal is indexed on PubMed Central, the 'PsycINFO' database and CAS,

\section{Dovepress}

and is the official journal of The International Neuropsychiatric Association (INA). The manuscript management system is completely online and includes a very quick and fair peer-review system, which is all easy to use. Visit http://www.dovepress.com/testimonials.php to read real quotes from published authors. 